\title{
Tratamentos para superar a dormência de sementes de tento
}

\author{
Valeria Veras Ribeiro* \\ Maria do Socorro Souto Braz \\ Noelma Miranda de Brito \\ Universidade Federal da Paraíba (UFPB), Centro de Ciências Agrárias (CCA) \\ CEP 58397000, Areia - PB, Brasil \\ *Autor para correspondência \\ valeria_vr@hotmail.com
}

Submetido em 16/09/2008

Aceito para publicação em 18/06/2009

\section{Resumo}

O trabalho teve por objetivo avaliar a influência de tratamentos pré-germinativos para superar a dormência exógena (impermeabilidade tegumentar) de sementes de tento (Adenanthera pavonina L.). Os experimentos foram realizados no Laboratório de Análise de Sementes e em Casa de Vegetação do Departamento de Fitotecnia do CCA-UFPB, em Areia-PB, em delineamento inteiramente casualizado com os tratamentos distribuídos em quatro repetições de 25 sementes para os dois ambientes. Os tratamentos foram: escarificação mecânica com lixa de ferro; imersão em ácido sulfúrico concentrado (98\%) por 15 e 30 minutos e testemunha (sem tratamento prévio das sementes). Em laboratório as sementes foram incubadas a $25^{\circ} \mathrm{C}$, distribuídas em papel umedecido, e em casa de vegetação foram semeadas em bandejas plásticas, contendo areia. As características analisadas foram: porcentagem de germinação, primeira contagem da germinação, comprimento de raiz e da parte aérea, peso de massa seca da raiz e parte aérea. Diante dos resultados, observou-se que os tratamentos de imersão em ácido sulfúrico por 15 e 30 minutos e a escarificação mecânica mostraram-se os mais eficientes para superação da dormência dessas espécies.

Unitermos: germinação, superação de dormência, vigor

\section{Abstract}

Treatments to prevent the dormancy of tento seeds. This work aimed to evaluate the influence of pre-germinative treatments on the prevention of tento seed dormancy (water impermeability of the seed coat). Accordingly an experiment was conducted at the Laboratory of Seed Analysis and Greenhouse of the Department of Fhytotechics of CCA-UFPB, in Areia-PB, in a completely randomized design with 4 replications of 25 seeds for the two environments. The treatments were: mechanical scarification with emery cloth, immersion in concentrated sulfuric acid $(98 \%)$ ) for 15 and 30 minutes, and the control (without previous treatment of the seeds). In the laboratory, the seeds were incubated at $25^{\circ} \mathrm{C}$ in damp paper, and in the greenhouse they were sown in plastic trays among sand. Germination and vigor tests were used, and the following parameters were analyzed: percentage of germination, first germination count, and length and day weight of the root and aerial parts of the seedlings. The results indicated that the immersion treatments in sulfuric acid for 15 and 30 minutes and the scarification were the most efficient in preventing seed dormancy.

Key words: germination, prevention of dormancy, vigor 


\section{Introdução}

A espécie Adenanthera pavonina L., popularmente conhecida como olho-de-dragão, tento-vermelho, carolina, sagauê, pertence à família Fabaceae e subfamília Mimosoideae. É uma espécie originária da Ásia e África. A árvore é recomendada para arborização paisagista, sua madeira é indicada para confecção de embalagens, tábuas para divisórias internas, cabo de ferramenta bem como para lenha (Silva e Lemos, 2002).

A produção de sementes florestais, principalmente no Nordeste brasileiro, tem sido nos últimos anos, uma das maiores dificuldades para implantação de plantios florestais, seja para obtenção de produtos diversos como lenha, carvão, madeira para serraria, cercas, moirões e alimento para gado, seja para melhorar a qualidade dos solos e das águas (IBAMA, 1998). A utilização de qualquer espécie florestal não-tradicional para plantios, com finalidade produtiva e, ou, ambiental, requer o desenvolvimento de tecnologia adequada de produção, iniciando pelo conhecimento da qualidade da semente (Leonhardt et al., 2001).

Para Borges et al. (1982) as sementes de várias espécies florestais apresentam dormência, constituindose esse fenômeno, em condições naturais, como importante mecanismo de sobrevivência, uma vez que conseguem livrar as sementes de períodos inóspitos para sua germinação. A importância ecológica da dormência baseia-se principalmente no bloqueio da germinação, quando as condições ambientais são adequadas à germinação, porém as perspectivas de futuro estabelecimento e crescimento das plântulas não são promissores; é importante, também, para distribuição da germinação de um lote de sementes no tempo e no espaço (Eira e Caldas, 2000). As causas da dormência podem ser as presenças de embriões imaturos e de tegumentos impermeáveis à água ou ao oxigênio, por restrições mecânicas ou pela presença de substâncias inibidoras da germinação (Bewley e Black, 1994). As sementes da maioria das espécies germinam prontamente quando lhes são dadas condições ambientais favoráveis (Carvalho e Nakagawa, 2000). No entanto, as sementes de cerca de dois terços das espécies arbóreas apresentaram certo grau de dormência, que pode ser superada com a utilização de tratamentos pré-germinativos.
A impermeabilidade do tegumento pode ocorrer devido à presença de uma cutícula e de uma camada bem desenvolvida de células em paliçada, ou de ambas (Copeland e McDonald, 1995), o que impede a absorção de água e impõe uma restrição mecânica ao crescimento do embrião, retardando o processo de germinação. Sob condições naturais, este tipo de dormência pode ser superado por processos de escarificação (Mayer e Polijakoff-Mayber, 1989), por ingestão pelos animais, pela atividade de microrganismos, pela acidez natural do solo e pelas queimadas (Copeland e McDonald, 1995), os quais provocam a ruptura ou o enfraquecimento do tegumento, permitindo a entrada de água e gases e o início da germinação.

Entre os métodos utilizados para superação da dormência tegumentar, a escarificação mecânica é uma técnica frequentemente utilizada e constitui a opção mais prática e segura para pequenos agricultores (Hermansen et al., 2000), além de ser um método simples, de baixo custo e eficaz para promover uma rápida e uniforme germinação. No entanto, deve ser efetuada com muito cuidado para evitar que a escarificação excessiva possa causar danos ao tegumento e diminuir a germinação (McDonald e Copeland, 1997). A escarificação mecânica do tegumento foi eficiente na superação da dormência das sementes de várias espécies com tegumento impermeável, como as de Erythrina velutina Willd. (Silva e Matos, 1993), Psidium araça Raddi (Cruz et al., 1997), Paspalum paniculatum L. (Lula et al., 2000) e Sterculia foetida L. (Santos et al., 2004). Para superar a dormência, vários métodos podem ser utilizados, sendo os mais comuns: embebição em água, retirada do tegumento, desponte (corte do tegumento), furo do tegumento, escarificação mecânica, imersão em água quente ou fria, água oxigenada, escarificação química com ácido sulfúrico, ácido clorídrico, soda, acetona e álcool (Santarém e Áquila, 1995).

O tratamento com ácido sulfúrico tem sido utilizado, com sucesso, na superação da dormência de Guazuma ulmifolia Lam. (Araújo Neto e Aguiar, 2000). Borges et al. (2004) observaram que o sucesso do tratamento está relacionado com o tempo de exposição ao ácido e à espécie quando pesquisaram as sementes de Tachigalia multijuga (Benth.). Bewley e Black (1994) reconhecem 
três tipos de dormência em sementes: dormência imposta pelo tegumento, dormência devido ao embrião (subdesenvolvido ou subdiferenciado) e dormência devido a substâncias promotoras e inibidoras. Entre os processos mais comuns para superação da dormência de sementes estão a escarificação química, escarificação mecânica, estratificação fria e quente-fria, choque térmico, exposição à luz intensa, imersão em água quente e embebição em água fria (Fowler e Bianchetti, 2000). Pelo exposto, o trabalho teve por objetivo avaliar a influência de tratamentos pré-germinativos para superar a dormência exógena (impermeabilidade tegumentar) de sementes de tento (Adenanthera pavonina L.).

\section{Material e Métodos}

O experimento foi conduzido no Laboratório de Análise de Sementes e Casa de Vegetação do Departamento de Fitotecnia do Centro de Ciências Agrárias da Universidade Federal da Paraíba, Areia $\mathrm{PB}$, com as sementes coletadas neste município. Após beneficiamento manual, as sementes foram inicialmente desinfestadas com solução de hipoclorito de sódio a $1 \%$ durante $5 \mathrm{~min}$, em seguida foram lavadas com água corrente e postas à sombra para secar. Após secagem determinou-se o peso de mil sementes (10 sub-amostras de 100 sementes), as quais foram pesadas em balança de precisão, segundo recomendações das Regras para Análise de Sementes (Brasil, 1992). Avaliou-se o teor de umidade com base na massa fresca (duas sub-amostras de 25 sementes).

\section{Teste de Germinação}

As sementes foram submetidas aos seguintes tratamentos para superação de dormência: T1 Testemunha (sem tratamento); T2 - Imersão em $\mathrm{H}_{2} \mathrm{SO}_{4}$ concentrado a 98\% (15 minutos); T3 - Imersão em $\mathrm{H}_{2} \mathrm{SO}_{4}$ concentrado a $98 \%$ (30 minutos); T4 - Escarificação mecânica com lixa de ferro $n^{\circ} 60$, na região oposta ao hilo. Em seguida, foram semeadas em rolo de papel umedecido com água destilada 2,5 vezes o peso do papel no sistema de rolos, no qual permaneceram em germinador, à temperatura constante de $25^{\circ} \mathrm{C}$, durante 28 dias após semeadura. Foram consideradas germinadas as sementes que apresentaram radícula medindo $0,5 \mathrm{~cm}$ após semeadura. Utilizou-se como critério de plântulas normais as que apresentavam as estruturas essenciais perfeitas (Brasil, 1992). As leituras foram realizadas diariamente a cada 24 horas. Após a emissão das primeiras folhas, os tratamentos em rolo de papel, foram descartados.

Avaliou-se porcentagem de germinação, primeira contagem, índice de velocidade de germinação (IVG), conforme a metodologia de Maguire (1962). Em casa de vegetação, as sementes foram submetidas aos mesmos tratamentos utilizados para Laboratório, sendo em seguida semeadas em bandejas plásticas, perfuradas no fundo, contendo areia, previamente peneirada, esterilizada e autoclavada, sendo umedecida com água equivalente a $60 \%$ da capacidade de retenção. Os parâmetros avaliados foram:

Emergência - considerou-se como emergidas as plântulas que apresentavam os cotilédones totalmente livres, realizando-se a leitura durante 28 dias. Consideraram-se como plântulas normais, as que apresentaram as estruturas vegetativas perfeitas (Brasil, 1992).

Primeira contagem - foi realizada conjuntamente com o teste de emergência e constou do registro da porcentagem de plântulas normais no sétimo dia após a instalação do teste.

Índice de Velocidade de Emergência (IVE) - as contagens foram realizadas diariamente, durante 28 dias para as plântulas normais, calculado conforme fórmula proposta por Maguire (1962).

Massa de matéria fresca e seca da parte área e da raiz das plântulas - a massa fresca e seca das plântulas foram determinadas em balança de precisão de $0,001 \mathrm{~g}$, sendo os resultados expressos em g/plântula.

Os testes de germinação e vigor foram conduzidos em delineamento inteiramente casualizado, com quatro repetições de 25 sementes, para cada tratamento. As médias foram comparadas pelo teste de Tukey a 5\% de probabilidade. Os resultados em porcentagem foram transformados em arco seno. Para a análise estatística utilizou-se o SAEG (Software Analysis and Experimentation Group (1997). 


\section{Resultados e Discussão}

O peso de mil sementes da espécie Adenanthera pavonina foi de $27,45 \mathrm{~g}$ e a umidade inicial das sementes foi de $76,15 \%$.

\section{Laboratório}

Os resultados encontrados neste ensaio mostram que os tratamentos com ácido sulfúrico por um período de 15 e 30min e a escarificação mecânica, não diferiram entre si pelo teste de Tukey a $5 \%$ de probabilidade, quanto à germinação das sementes de tento com 95, 100 e 96\%, respectivamente (Tabela 1). Indicando que todos os métodos utilizados interferiram positivamente na ruptura tegumentar das sementes de tento, favorecendo a germinação em relação às sementes da testemunha, que apresentaram $8 \%$ de germinação, indicando que para essa espécie o tempo de exposição ao ácido sulfúrico não ocasionou danos ao embrião da semente. Resultados encontrados por Kissmann et al. (2008), com sementes de tento, indicaram a utilização do ácido sulfúrico como método eficiente na quebra da dormência dessa espécie. Borges et al. (2004) afirmam que o sucesso do tratamento está relacionado com o tempo de exposição ao ácido e à espécie. Os resultados observados por Lopes et al. (1998) com a utilização do ácido sulfúrico na superação de dormência de três espécies florestais Caesalpinea férrea Mart. ex. Tul. var. leiostachya Benth., Cassia grandis L. e Samanea saman Merrill observaram que a imersão das sementes dessas espécies por 5 e $60 \mathrm{~min}$ foram os responsáveis pelos maiores percentuais de germinação. Já o uso de ácido sulfúrico durante 15 ou 20 min em sementes de Leucaena leucocephala resultou em porcentagem de germinação acima de $90 \%$ (Teles et al., 2000), o que também foi observado quando se utilizou ácido sulfúrico aos 15 e 30min.

De acordo com Nassife Perez (1997), os tratamentos de escarificação mecânica tiveram efeitos significativos no aumento da germinação imediata das sementes de Pterogyne nitens Tul, sendo este método, juntamente com os químicos, como a imersão em ácido sulfúrico os mais eficientes em superar a dormência e promover a germinação das sementes desta espécie. Já Santos et al. (2004) observaram que a utilização da escarificação mecânica promoveu a quebra da dormência de Sterculia foetida L., proporcionando aumento na percentagem de geminação de sementes de $70 \%$. Resultados encontrados por Martinelli-Seneme et al. (2006), com sementes de Bauhinia variegata, também demonstraram aumento na percentagem de germinação com $99 \%$ após o uso da escarificação mecânica das sementes.

TABELA 1: Germinação, Primeira Contagem e Índice de Velocidade de Germinação de sementes de tento (A. pavonina) em laboratório, submetidas a tratamentos pré-germinativos com ácido sulfúrico e escarificação mecânica.

\begin{tabular}{lccc}
\hline Tratamentos & $\begin{array}{c}\text { Germinação } \\
(\%)\end{array}$ & $\begin{array}{c}\text { Primeira } \\
\text { Contagem } \\
(\%)\end{array}$ & IVG \\
\hline $\begin{array}{l}\text { Testemunha } \\
\begin{array}{l}\text { Ácido Sulfúrico } \\
\text { (15min) }\end{array}\end{array}$ & $8 \mathrm{~b}$ & $8 \mathrm{c}$ & $1,0 \mathrm{~b}$ \\
$\begin{array}{l}\text { Ácido Sulfúrico } \\
\text { (30min) }\end{array}$ & $100 \mathrm{a}$ & $80 \mathrm{a}$ & $4,8 \mathrm{a}$ \\
$\begin{array}{l}\text { Escarificação } \\
\text { mecânica }\end{array}$ & $96 \mathrm{a}$ & $71 \mathrm{a}$ & $4,7 \mathrm{a}$ \\
\hline CV\% & 4,6 & 15,1 & 35,6 \\
\hline DMS & 7,3 & 16,7 & 2,7 \\
\hline
\end{tabular}

Colunas seguidas pela mesma letra, não diferem entre si, pelo teste de Tukey a $5 \%$ de probabilidade.

Para os valores referentes ao vigor, determinado na primeira contagem de germinação, os tratamentos que se destacaram foram o ácido sulfúrico por 30 minutos $(80 \%)$ e a escarificação mecânica $(71 \%)$, diferindo estatisticamente do tratamento com ácido sulfúrico por 15 minutos (52\%) e da testemunha ( $8 \%$ ), causando a ruptura e/ou fissura do tegumento das sementes eliminando a impermeabilidade, sem causar alterações fisiológicas (Tabela 1). Os resultados encontrados por Kissmann et al. (2008), em relação a primeira contagem de germinação, indicaram que as sementes imersas em ácido sulfúrico germinaram mais rápido em relação as sementes da testemunha. Bruno et al. (2001), avaliando a dormência em sementes de Mimosa caesalpiniaefolia Benth., concluíram que os tratamentos de imersão em ácido sulfúrico por 10 ou $13 \mathrm{~min}$ e o desponte na região oposta ao eixo embrionário proporcionaram elevadas porcentagens de primeira contagem. Os resultados 
observados por Roversi et al. (2002) com sementes de Acacia mearnsii Willd, apresentaram como melhores resultados da primeira contagem, o tratamento prégerminativo com a escarificação mecânica. Outros resultados semelhantes foram constatados por Piroli et al. (2005) com sementes de Peltophorum dubium (Spring.) Taub., utilizando a escarificação mecânica e o ácido sulfúrico.

$\mathrm{Na}$ avaliação do IVG, observa-se que os tratamentos de imersão das sementes em ácido sulfúrico por $15 \mathrm{~min}$ (4.0), ácido sulfúrico por $30 \mathrm{~min}(4,8)$ e escarificação mecânica $(4,7)$ estatisticamente não diferiram entre si, embora tenham apresentado maiores valores em relação a testemunha (1.0) na avaliação para a superação de dormência das sementes de tento (Tabela 1). Resultados semelhantes foram observados por Kissmann et al. (2008) com essa espécie ao verificaram que a imersão das sementes em ácido sulfúrico por 10 e $20 \mathrm{~min}$ proporcionaram maior IVG. Smiderle e Sousa (2003) obtiveram maiores valores para o Índice de Velocidade de Germinação quando utilizaram os tratamentos com ácido sulfúrico por 5 e 10min e escarificação com lixa em sementes de Bowdichia virgilioides

Resultados observados por Lopes et al. (2006), estudando tratamentos pré-germinativos para superação de dormência de sementes de Ormosia nitida, verificaram que a escarificação mecânica e a química com ácido sulfúrico por $10 \mathrm{~min}$, determinaram aumento acentuado na velocidade e percentagem de germinação das sementes em relação ao controle.

\section{Casa de Vegetação}

Para emergência de $A$. pavonina, todos os tratamentos apresentaram diferenças significativas quando comparadas com a testemunha (8\%). Entre os tratamentos, destacaram-se os com ácido sulfúrico por um período de 15 e $30 \mathrm{~min}$ (91 e $83 \%$ ), respectivamente (Tabela 2), não ocorrendo diferenças significativas entre os tratamentos. A eficiência de tratamentos de imersão em ácido sulfúrico, para reduzir a taxa de dormência, foi também constatada em sementes de Bowdichia virgilioide H.B.K. (Sampaio et al., 2001); em sementes de Caesalpinia pyramidalis Tul (Alves et al., 2007) e por Santos et al. (2003) com sementes de Smilax japecanga.

Lopes et al. (2006) observaram que todos os tratamentos utilizados na superação da dormência de sementes de $O$. nitida, apresentaram respostas positivas na percentagem e velocidade de germinação em relação ao controle. Os valores médios da germinação evidenciaram que os tratamentos feitos com escarificação mecânica não diferiram estatisticamente do controle e que a utilização do ácido sulfúrico, embora tenha elevado à percentagem de germinação apresentou resultados estatisticamente similares aos tratamentos com escarificação mecânica.

Para os valores referentes ao vigor, determinado pela primeira contagem de emergência, o tratamento que se se destacou foi com ácido sulfúrico por 30 minutos (44\%), seguido do tratamento escarificação mecânica (38\%) (Tabela 2). A utilização da escarificação mecânica

TABELA 2: Emergência, primeira contagem, Índice de Velocidade de Emergência, matéria seca da raiz e parte aérea de sementes de tento (A. pavonina) em casa de vegetação, submetidas a tratamentos prégerminativos com ácido sulfúrico e escarificação mecânica.

\begin{tabular}{lcccc}
\multicolumn{1}{c}{ Tratamentos } & Emergência (\%) & $\begin{array}{c}\text { Primeira Conta- } \\
\text { gem (\%) }\end{array}$ & $\begin{array}{c}\text { Matéria seca da } \\
\text { raiz (g) }\end{array}$ & $\begin{array}{c}\text { Matéria seca da } \\
\text { parte aérea }(\mathbf{g})\end{array}$ \\
\hline Testemunha & $8 \mathrm{c}$ & $5 \mathrm{~d}$ & $0,05 \mathrm{c}$ & $0,5 \mathrm{a}$ \\
Ácido Sulfúrico (15min) & $91 \mathrm{a}$ & $11 \mathrm{c}$ & $0,4 \mathrm{a}$ & $2,0 \mathrm{a}$ \\
Ácido Sulfúrico (30min) & $83 \mathrm{a}$ & $44 \mathrm{a}$ & $0,3 \mathrm{ab}$ & $2,0 \mathrm{a}$ \\
Escarificação mecânica & $60 \mathrm{~b}$ & $38 \mathrm{~b}$ & $0,2 \mathrm{bc}$ & $1,2 \mathrm{a}$ \\
\hline CV\% & 12,9 & 11,44 & 32,1 & 51,9 \\
\hline DMS & 16,4 & 5,8 & 0,1 & 1,5 \\
\hline
\end{tabular}

Colunas seguidas pela mesma letra, não diferem entre si, pelo teste de Tukey a 5\% de probabilidade. 
mostrou-se eficiente, sem causar danos a semente, assim como o ácido sulfúrico. Porém, de acordo com Medeiros Filho et al. (2002) afirmam que a escarificação mecânica pode ocasionar injúrias nas sementes pela fricção ou diferença de constituição de seus tegumentos em função da espécie e que a utilização de material abrasivo exige cuidados quanto à intensidade e à forma de aplicação, para não comprometer a qualidade das sementes.

Bruno et al. (2001), estudando sementes claras e escuras de Mimosa caesalpiniaefolia, constataram que, nas sementes claras, os tratamentos de imersão em ácido sulfúrico e escarificação ácida apresentaram elevados valores de primeira contagem. Martins et al. (2001) pesquisando dormência em Mimosa escabrela observaram que a escarificação com lixa e imersão em $\mathrm{H}_{2} \mathrm{SO}_{4}$ por $15 \mathrm{~min}$, possibilitaram o aumento da velocidade de germinação pelo resultado de primeira contagem. Não foram observadas diferenças significativas entre o tratamento com ácido sulfúrico por $15 \mathrm{~min}$ e o tratamento testemunha (10 e 6\%), respectivamente.

Com relação à matéria seca da raiz, os tratamentos utilizados apresentaram diferenças estatísticas com relação ao tratamento testemunha $(0,05 \mathrm{~g})$ pelo teste de Tukey a $5 \%$ de probabilidade. Os melhores resultados foram observados com a utilização de ácido sulfúrico por $15 \mathrm{~min}(0,4 \mathrm{~g})$, não diferindo do tratamento com ácido sulfúrico por $30 \mathrm{~min}(0,3 \mathrm{~g})$ (Tabela 2). Santos et al. (2004), avaliando a massa seca do sistema radicular em sementes de chichá (Sterculia foetida), observaram que a escarificação dos dois lados sem embebição e com embebição por $24 \mathrm{~h}$, com um lado sem embebição e com embebição por $24 \mathrm{~h}$, não houve diferença significativa entre estes tratamentos.

Em relação à matéria seca da parte aérea, os melhores resultados foram observados com os tratamentos com ácido sulfúrico por 15 e $30 \mathrm{~min}(2 \mathrm{~g})$, não sendo encontradas diferenças significativas entre todos os tratamentos (Tabela 2). Medeiros Filho et al. (2005) relatam que plântulas de Caesalpinia ferrea provenientes de sementes tratadas com ácido sulfúrico, não apresentaram diferenças estatísticas quanto à massa seca da parte aérea, com relação ao controle, porém, estas apresentaram maior peso seco, que as desenvolvidas em germinador. Já Pereira et al. (2007) relatam que não houve diferenças estatísticas entre os tratamentos para superação de dormência em sementes de Merremia aegyptia, quando avaliadas a massa seca da parte aérea das plântulas.

Segundo Santos et al. (2004), as sementes que foram submetidas à escarificação em um lado, seguida de embebição, originaram plântulas com maior massa seca da parte aérea do que a escarificação nos dois lados da semente, sem embebição, não diferindo da testemunha (sementes intactas), nem da escarificação nos dois lados sem embebição.

Dentre os tratamentos realizados, a imersão em ácido sulfúrico por 15 e $30 \mathrm{~min}$ e a escarificação mecânica mostraram-se mais eficientes em promover a superação da dormência das sementes de A. pavonina e, em consequência promoveram aumento da percentagem de germinação, primeira contagem e IVG em condições de laboratório. Para as análises em casa de vegetação os tratamentos com ácido sulfúrico por 15 e $30 \mathrm{~min}$ mostram-se mais eficientes em promover a aumento na emergência das sementes e no acúmulo de matéria seca da raiz e da parte aérea das plântulas. Em relação à primeira contagem os melhores tratamentos foram a imersão em ácido sulfúrico por $15 \mathrm{~min}$ e a escarificação mecânica.

\section{Agradecimentos}

As autoras agradecem ao Engenheiro Agrônomo Antônio Alves de Lima e aos laboratoristas Rui Barbosa da Silva, Severino Francisco dos Santos e Inaldo de Oliveira que viabilizaram a execução deste trabalho.

\section{Referências}

Alves, E. U.; Cardoso, E. A.; Bruno, R. L. A.; Alves, A. U.; Alves, A. U.; Galindo, E. A.; Braga, J. M. 2007. Superação de dormência em sementes de Casealpinia pyramidalis Tul. Revista Árvore, 31 (3): 405-415.

Araujo Neto, J. C.; Aguiar, I. B. 2000. Tratamentos pré-germinativos para superar a dormência de sementes de Guazuma ulmifolia Lam. Scientia Forestalis, 58 (1): 15-24.

Bewley, J. D.; Black, M. 1994. Seeds: Physiology of development and germination. Plenum Press, New York, USA, 445pp.

Borges, E. E. L.; Borges, R. C. G.; Cândido, J. F.; Gomes, J. M. 1982. Comparação de métodos de quebra de dormência em sementes de copaíba. Revista Brasileira de Sementes, 4 (1): 9-12. 
Borges, E. E. L.; Ribeiro Júnior, J. I.; Rezende, S. T.; Perez, S. C. J. G. A. 2004. Alterações fisiológicas em sementes de Tachigalia multijuga (Benth.) (Mamoneira) relacionadas ao método para a superação da dormência. Revista Árvore, 28 (3): 317-325.

Brasil - Ministério da Agricultura e Reforma Agrária. 1992. Regras para análise de sementes. SNDA/DNDV/CLAV, Brasília, Brasil, 365pp.

Bruno, R. L. A.; Alves, E. U.; Oliveira, A. P.; Paula, R. C. 2001 Tratamentos pré-germinativos para superar a dormência de sementes de (Mimosa caesalpiniaefolia Benth.). Revista Brasileira de Sementes, 23 (2): 136-143.

Carvalho, N. M.; Nakagawa, J. 2000. Sementes: Ciência, tecnologia e produção. FUNEP, Jaboticabal, Brasil, 588pp.

Copeland, L. O.; McDonald, M. B. 1995. Seed science and technology. Chapmam e Hall, New Jersey, USA, 409pp.

Cruz, G. R. B.; Matos, V. P.; Gonçalves, E. P. 1997. Germinação de sementes de araçá (Psidium araça Raddi-Myrtaceae): Tratamentos pré-germinativos. Informativo ABRATES, 7 (1/2): 259.

Eira, M. T. S.; Caldas, L. S. 2000. Seed dormancy and germination as concurrent processes. Revista Brasileira de Fisiologia Vegetal, 12 (1): 85-104. (Edição especial).

Fowler, J. A. P.; Bianchetti, A. 2000. Dormência em sementes florestais. doc. 40. EMBRAPA-Florestas, Colombo, Brasil, 27pp.

Hermansen, L. A.; Duryea, M. L.; White, T. L. 2000. Variability in seed coat dormancy in Dimorphandra mollis. Seed Science Technology, 28 (3): 567-580.

IBAMA - Instituto Brasileiro do Meio Ambiente. 1998. Sementes florestais: Colheita, beneficiamento e armazenamento. Ministério do Meio Ambiente, Brasília, Brasil, 26pp.

Leonhardt, C.; Tillmann, M. A. A.; Villela, F. A.; Mattei, V. L. 2001. Maturação fisiológica de sementes de turamã-de-espinho (Citharexylum montevidense (Spreng.) Moldenke - Verbenaceae), no Jardim Botânico de Porto Alegre, RS. Revista Brasileira de Sementes, 23 (1): 100-107.

Lopes, J. C.; Capucho, M. T.; Krohling, B.; Zanotti, P. 1998. Germinação de sementes de espécies florestais de Caesalpinia férrea Mart. Ex Tul. var. leiostachya Benth., Cassia grandis L. e Samanea saman Merrill, após tratamentos para superar a dormência. Revista Brasileira de Sementes, 20 (1): 80-86.

Lopes, J. C.; Dias, P. C.; Macedo, C. M. P. 2006. Tratamento para acelerar a germinação e reduzir a deterioração das sementes de Ormosia nitida Vog. Revista Árvore, 30 (2): 171-177.

Lula, A. A.; Alvarenga, A. A.; Almeida, L. P.; Alves, J. D.; Magalhães, M. M. 2000. Estudos de agentes químicos na quebra de dormência de sementes de Paspalum paniculatum L. Ciências e Agrotecnologia, 24 (2): 358-366.

Kissmann, C.; Scalon, S. P. Q.; Filho, H. S.; Ribeiro, N. 2008. Tratamentos para a quebra de dormência, temperaturas e substratos na germinação de Adenanthera pavonina L. Ciência e Agrotecnologia, 32 (2): 668-674.

Maguire, J. D. 1962. Speed of germination aid in selection and evaluation for seedling emergence and vigor. Crop Science, 2 (2): 176-177.

Martins, C. C.; Seneme, A. M.; Mori, E. S.; Nakagawa, J.; Cavariani, C. 2001. Métodos de superação de dormência em sementes de Bracatinga (Mimosa escabrela). Informativo ABRATES, 11 (2): 250.
Martinelli-Seneme, A.; Possamai, E.; Schita, L. R.; Vanzolini, S. 2006. Germinação e sanidade de sementes de Bauhinia variegata. Revista Árvore, 30 (5): 719-724.

Mayer, A. M.; Polijakoff-Mayber, A. 1989. The germination of seeds. $4^{\text {th }}$ ed. Pergamon Press, London, UK, 270pp.

McDonald, M. B.; Copeland, L. O. 1997. Seed production: Principles and practices. Chapmam e Hall, New Jersey, USA, 749pp.

Medeiros Filho, S.; França, E. A.; Innecco, R. 2002. Germinação de sementes Operculinia macrocarpa (L.) Farwel e Operculinia alata (Ham.) Urban. Revista Brasileira de Sementes, 24 (2): 102-107.

Medeiros Filho, S.; Silva, M. A. P.; Santos Filha, M. E. C. 2005. Germinação de sementes e desenvolvimento de plântulas de plântulas de Caesalpinia ferrea Mart. Ex Tul var. ferrea em casa de vegetação e germinador. Revista Ciência Agronômica, 36 (2): 203-208

Nassif, S. M. L.; Perez, S. C. J. G. A. 1997. Germinação de sementes de amendoim-do-campo (Pterogyne nitens Tul.): influência dos tratamentos para superar a dormência e profundidade de semeadura. Revista Brasileira de Sementes, 19 (2): 171-178.

Pereira, E. W. L.; Ribeiro, M. C. C.; Souza, J. O.; Linhares, P. C. F.; Nunes, G. H. S. 2007. Superação de dormência em sementes de jitirana (Merremia aegyptia L.). Revista Caatinga, 20 (2): 59-62.

Piroli, E. L.; Custódio, C. C.; Rocha, M. R. V.; Udenal, J. L. 2005. Germinação de sementes de canafístula Peltophorum dubium (Spreng.) Taub. Tratadas para superação da dormência. Colloquium Agrariae, 1 (1): 13-18.

Roversi, T.; Mattei, V. L.; Silveira Júnior, P.; Falck, G. L. 2002. Superação da dormência em sementes de Acácia negra (Acácia mearnsii willd.). Revista Brasileira de Agrociência, 8 (2): 161163.

SAEG - Software Analysis and Experimentation Group). 1997. Sistema para Análises Estatísticas. Versão 7.0. Fundação Arthur Bernardes, Viçosa, Brasil, s/paginação.

Sampaio, L. S. V.; Peixoto, C. P.; Peixoto, M. F. S. P.; Costa, J. A.; Garrido, M. S.; Mendes, L. N. 2001. Ácido sulfúrico na superação da dormência de sementes de sucupira-preta (Bowdichia virgilioides H.B.K. - Fabaceae). Revista Brasileira de Sementes, 23 (1): 184190.

Santarém, E. R.; Áquila, M. E. A. 1995. Influência de métodos de superação de dormência e do armazenamento na germinação de sementes de Senna macranthera (Colladon) Irwin e Barneby (Leguminosae). Revista Brasileira de Sementes, 17 (2): 205-209. Santos, M. R. A.; Paiva, R.; Gomes, G. A. C.; Paiva, P. D. O.; Paiva, L. V. 2003. Estudos sobre superação de dormência em sementes de Smilax japecanga Grisebach. Ciência e Agrotecnologia, 27 (2): 319-324.

Santos, T. O.; Morais, T. G. O.; Matos, V. P. 2004. Escarificação mecânica em sementes de chichá (Sterculia foetida L.). Revista Árvore, 28 (1): 1-6.

Silva, D. B.; Lemos, B. S. 2002. Plantas de área verde da Super Quadra Norte 416, Brasília, DF. EMBRAPA, Recursos Genéticos e Biotecnologia, Brasília, Brasil, 147pp.

Silva, L. M. M.; Matos, V. P. 1993. Estudo sobre dormência de sementes de mulungu (Erythrina velutina Willd.): viabilidade e presença de inibidores. Ciência Agrícola, 2 (1): 29-40. 
Smiderle, O. J.; Sousa, R. C. P. 2003. Dormência em sementes de paricarana (Bowdichia virgilioides Kunth-Fabaceae-Papilionidae). Revista Brasileira de Sementes, 25 (1): 72-75.

Teles, M. M.; Alves, A. A.; Oliveira, J. C. G.; Bezerra, A. M. E. 2000. Métodos para quebra da dormência em sementes de leucena (Leucaena leucephala (Lam.) de Wit). Revista Brasileira de Zootecnia, 29 (2): 387-391. 